\title{
Deu Zika no Toca: Como o jornal de maior circulação do estado do Tocantins veiculou as notícias sobre a epidemia nos anos de 2015 a 2018.
}

Resumo: O estudo analisa o panorama dos textos jornalísticos veiculados acerca da epidemia de Zika no jornal de maior circulação do estado do Tocantins no período de janeiro de 2015 a dezembro de 2018. Foi realizada uma análise de conteúdo qualiquantitativa e encontrados 44 textos sobre a temática. Identificou-se que a maior quantidade de informações do jornal se refere a prevenção à doença e divulgação do número de casos no estado e no Brasil, a relação do vírus Zika com a microcefalia em bebês também foi tema central dá cobertura. Indentificou-se ainda uma culpabilização da sociedade pela epidemia de zika e pouca oportunidade de fala da população no jornal. A forma como uma notícia é veiculada produz significados distintos nos leitores, da mobilização popular e o esclarecimento à disseminação de medo e preocupação. Por esse motivo, é importante que a abordagem jornalística traduza os dados epidemiológicos de forma fidedigna e com qualidade para a população.

Palavras-chave: Comunicação em Saúde, Zika Vírus, Jornalismo, Saúde pública .

\section{Zika Virus: As the newspaper of greater circulation of the state of Tocantins} transmitted the news on the epidemic in the years of 2015 to 2018.

Abstract: The epidemic situation of the Zika virus in 2015 has created a scenario of uncertainties about the disease, in this sense the media have an important role in the dissemination of reliable news. In this sense, the present study aims to analyze the panorama of the journalistic texts about the Zika epidemic in the newspaper of greatest circulation in the state of Tocantins from January 2015 to December 2018. A documental analysis of the qualitative approach was carried out, following the methodological reference of the content analysis according to Bardin. A major concern of the newspaper was identified with disease prevention and disclosure of the case number in the state and in Brazil. The relationship of the Zika virus with microcephaly in infants was also the central theme of the reports. It is understood that the form with the news is conveyed, produces distinct meanings in the readers that can produce a popular mobilization and the clarification of the people, or the spread of fear and constant concern. For this reason, it is important that the journalistic approach translates epidemiological data reliably and with quality for the population.

Key Word: Health Communication, Journalism, Zika Virus, Public health. 


\section{1) Introdução}

Os arbovírus são considerados fenômenos naturais de evolução e adaptação de espécies. Chegaram ao Brasil através de doenças caracterizadas como persistentes, a exemplo da febre amarela ou reemergentes, como a dengue, reintroduzida no país no início da década de 1980. Anos depois, outras doenças consideradas emergentes também se tornaram um problema de saúde pública por sua aparição no país, mais especialmente nas regiões norte e nordeste, são elas a febre chikungunya e o vírus zika.

A situação epidêmica do vírus zika em 2015, instaurou um cenário de incertezas a respeito do agravo. O zika é um arbovírus que tem especificidades em relação aos outros por influenciar diretamente o desenvolvimento da Microcefalia. Os efeitos do zika perpetuarão por gerações, o poder público, os profissionais de saúde e a população afetada terão que lidar com o problema e se prepararem para os desafios que se colocam.

No início da epidemia no Brasil, ocorreram rumores que geraram um estado de insegurança, por isso, a disseminação de informações confiáveis tornou-se fundamental para abordagem da situação ${ }^{1}$. O processo de disseminação de notícias confiáveis e verídicas sobre as questões de saúde pública é um dos espaços em que o campo da comunicação se une ao campo da saúde. Essa relação, porém, se dá de forma complexa, e as duas áreas, saúde e comunicação, demandam reflexões dos campos institucional e científico. É preciso trazer apontamentos sobre questões epistemológicas e metodológicas próprias do campo da saúde para construir uma informação consciente e confiável, que terá uma responsabilidade social com seus leitores ${ }^{2}$.

A responsabilidade social da imprensa é uma das preocupações da comunicação de risco. Esse tipo de comunicação tem como proposta melhorar o diálogo entre 
diferentes atores, como especialistas e população em geral, tentando produzir uma informação segura do que representa risco, principalmente no que diz respeito às arboviroses $^{3}$.

O interesse da mídia pela zika aumentou após a ocorrência de complicações nos casos de infecção pelo vírus. A epidemia passou a ser considerada uma síndrome, uma vez confirmados casos de Síndrome de Guillain-Barré e de infecção congênita, o que causou Microcefalia em bebês associados a infecção por zika vírus. Este cenário fez com que a doença se tornasse prioridade na agenda midiática nacional e latinoamericana, compondo o que se denomina como "ciclos midiáticos epidêmicos", visto que a enfermidade extrapola as divisões sociais e geográficas de outras doenças ao se transmitir com alta efetividade entre diferentes grupos ${ }^{4}$. No Brasil a epidemia foi mais grave nos estados das regiões Norte e Nordeste do país ${ }^{25}$.

A partir de então, os meios de comunicação brasileiros viram a necessidade de informar com maior recorrência sobre o arbovírus da zika. A utilização da comunicação de risco para informar a população sobre epidemias como a de zika seria o primeiro passo para uma comunicação de saúde pública segura ${ }^{3}$. No Brasil, dentre as unidades da federação o Tocantins foi o terceiro estado brasileiro com a maior taxa de incidência de prováveis casos de zika com 32,9 casos/mil habitantes de acordo com o boletim epidemiológico n ${ }^{\circ} 4$ de 2019 do Ministério da Saúde, os casos foram distribuídos em 12 cidades do estado e 4 delas entraram em situação de emergência. $O$ boletim epidemiológico é uma ferramenta que o Ministério da Saúde utiliza para descrever o cenário da dooença semanalmente e informar a população. Dentre os municípios com 100 a 500 mil habitantes, a cidade de Palmas teve maior incidência de casos prováveis da doença do país na semana epidemiológica 52, que corresponde ao período de 23 a 29 de dezembro de $2018^{6}$. 
Porém, os achados na literatura demonstram que estudos de comunicação em jornais impressos são realizados com maior frequência em jornais de grande circulação nacional ${ }^{4}$, que geralmente são do sudeste do país, por esse motivo, estudar um jornal do norte do país neste cenário epidemiológico é relevante para os estudos da comunicação em saúde.

Tendo em vista o contexto destacado, torna-se importante estudar como se deu a divulgação de notícias sobre a epidemia de zika no estado do Tocantins pela mídia impressa. Para isso, foi escolhido o jornal de maior circulação em todo o estado, intitulado Jornal do Tocantins (JTO). Atualmente, o JTO é o maior jornal impresso, tanto em número de páginas (15), como em tiragem que gira em torno de sete milhões de exemplares circulando no estado. O mesmo possui versão online, e é constituido por seis editorias específicos. Objetiva-se, neste estudo, analisar o panorama dos textos jornalísticos veiculados acerca da epidemia de zika de janeiro de 2015 a dezembro de 2018. 


\section{2) Método}

Trata-se de uma análise documental retrospectiva com abordagem qualiquantitativa. $\mathrm{O}$ corpus de análise foram textos jornalísticos sobre zika vírus do Jornal do Tocantins, publicados entre 2015 e 2018 no impresso e replicados no jornal online. A amostra foi definida de acordo com a conveniência do universo de origem. A intenção do estudo foi identificar e analisar as notícias sobre o tema estudado em todos os cadernos do jornal, visto que não há um caderno específico para saúde.

A coleta e análise dos dados seguiu o referencial metodológico de Laurence Bardin (1997), para quem a análise de conteúdo se divide em três momentos: $1^{\circ}$, préanálise dos dados; $2^{\circ}$, exploração do material; e $3^{\circ}$, tratamento dos resultados, inferência e interpretação ${ }^{7}$. As fases da análise de conteúdo foram seguidas com o auxílio do software de análise mista Maxqda 2018, que permite uma associação sistêmica de segmentos textuais a certos temas, pois, os dados encontrados podem ser divididos em categorias de análise através da criação de códigos e da possibilidade de escrever anotações sobre cada segmento encontrado. Esta ferramenta, torna viável a interpretação dos dados encontrados e comparações dos achados para a identificar a abordagem dada ao zika pela mídia impressa. As categorias de análise emergem a partir do que jornal traz de informações acerca do tema, e daí as ferramentas de análise do software permitem a identificação do que mais foi relevante, incluindo a frequência com que as informações apareceram.

Para nortear a análise da abordagem que o jornal dá à temática do arbovirus zika, foram definidos parâmetros estratégicos, para a partir deles, identificar o surgimento das categorias que surgiram através da abordagem do jornal. Os parâmetros foram: 1. "Foco na saúde ou na doença", com a intenção de identificar se notícias estão voltadas para promoção da saúde da população ou se as informações trazidas pelo periódico estão 
colocando o foco de suas informações nas consequências destas doenças podendo disseminar medo na comunidade leitora, 2. "Responsabilização e vozes sobre zika no jornal”, para saber se, ao noticiar sobre a situação da epidemia no estado do Tocantins, o jornal responsabiliza alguém e identifica quais desses entes (como governo, profissionais e sistema de saúde ou população) tem voz representada no jornal" 3 . “Abordagem dada à epidemia", ou seja, com qual população o jornal analisado conversa e para quem escreve e 4. "Relação da zika com Microcefalia", para identificar como há menção ao surgimento da microcefalia através da zika.

Foram observados ainda, os elementos gráficos presentes nos textos jornalísticos, se as notícias sobre zika que foram capa do jornal, e também o gênero jornalístico dessas informações, visto que estas categorias determinam a importância da temática para o jornal e interferir diretamente na visualização que o público leitor tem da situação.

Tendo os parâmetros de análise como norteadores da leitura dos textos jornalísticos, a abordagem do jornal foi identificada a partir dos conteúdos que emergiram nos textos. Os conteúdos foram codificados por segmentos de palavras, ou seja, cada assunto que surgia a partir da leitura flutuante dos textos jornalísticos foi relacionado ao parâmetro de análise correspondente através da codificação que permitia a separação de cada parâmetro por cores no software. O presente artigo não foi submetido ao comitê de ética em pesquisa pois trata-se de uma análise documental. 


\section{3) Resultados e Discussão}

Foram encontrados no período de quatro anos um total de 44 textos jornalísticos a respeito do zika vírus. Destes, 12 no ano de 2015, 20 em 2016, 9 em 2017 e apenas três textos no ano de 2018. Para identificação das categorias, os segmentos do texto foram codificados conforme o critério de análise correspondente. Ao todo foram 1.139 segmentos codificados, que formaram as categorias correspondentes aos parâmetros estabelecidos.

\section{O que emergiu nos Textos Jornalísticos?}

Percebeu-se que o periódico em questão deu prioridade a temáticas específicas ao noticiar sobre zika vírus. O assunto mais citado é prevenção, seguida do risco. As ações do governo, as características da doença e tratamento e recuperação apareceram em seguida, como demonstra a tabela 1:

Tabela I. Temáticas sobre Zika Vírus abordadas no jornal

\begin{tabular}{l|c}
\multicolumn{1}{c|}{ Tema Abordado } & No de codificações \\
\hline Prevenção & 63 \\
\hline Risco & 61 \\
\hline Ações do Governo & 39 \\
\hline Características da Doença & 39 \\
\hline Tratamento e Recuperação & 34 \\
\hline Fonte: Elaboração Própria.
\end{tabular}

É importante ressaltar que as ações de prevenção às doenças são aliadas à propagação da comunicação de risco. A melhor forma de combater o mosquito está na nos cuidados de prevenção e controle do vetor, e ficou claro que o JTO informa sobre a importância e as formas de prevenção. 
Em geral a mídia nacional, com exceção da Folha de São Paulo, pouco abordava o assunto até 2015 , logo percebe-se o posicionamento do JTO ao noticiar o zika associado à prevenção ${ }^{8}$. O jornal associou ações de prevenção às medidas de eliminação do vetor, tais como, a limpeza das casas, quintais e ruas, retirada de água parada de vasos de plantas, pneus, caixas d'água, uso de repelente por conta da associação do vírus e demais ações conforme o trecho abaixo:

“Temos que estar preparados para uma nova temporada de chuvas. Vamos manter o nível de combate (..) o mosquito ainda está aí. Cuidados diários podem evitar a proliferação do mosquito, como evitar água parada, vedar caixas d'água, manter garrafas vazias voltadas para baixo e sacos de lixo bem fechados"(JTO, 12/05/2017).

Desde a chegada do vírus no Brasil, a comunicação começou a ser usada como estratégia para garantir a transparência das informações dadas a população ${ }^{6}$. Por esse motivo, uma das preocupações do Ministério da Saúde era o surgimento de uma crise associada ao alarde midiático sobre a gravidade da doença. Mesmo assim, a informação sobre o risco causado pelo zika, foi um assunto que emergiu com muita frequência durante os anos de análise do jornal, abaixo apenas da prevenção. Comunicar risco requer uma responsabilidade social importante por parte do jornal, pois a depender da abordagem pode causar uma reação de medo na população que para ser esclarecida posteriormente, demanda esforços da imprensa.

Neste contexto é importante que o comunicador não reproduza uma cultura de medo associada à prevenção, pois o conceito de risco pode ser utilizado para veicular formas de prover segurança aos indivíduos, que devem seguir responsavelmente preceitos baseados em conceitos tomados como verdade sem discussão ou visão crítica. Deste modo, a ideia de prevenção não deve estar associada a uma procura constante de controle antecipatório dos riscos e gestão do medo, pois esses conceitos estão 
relacionados a uma necessidade de proteção diante de perigos que são obstinadamente reiterados por canais de comunicação dos riscos, o que pode causar culpabilização e ansiedade na população ${ }^{9}$.

O enfoque de risco dado pelo jornal teve relação com a probabilidade da comunidade se infectar com a doença, e as situações que colocavam as pessoas em situação de vulnerabilidade em relação a ela, como estar em espaços com água parada e lixo, ou a não utilização de repelente por parte de mulheres grávidas. O debate sobre risco relacionado ao zika ganhou novos contornos diante da dimensão da doença, ele é tratado com um acentuado grau de incerteza, por isso relaciona-se com a mudança de atitude da população na tentativa de evitar uma possibilidade de infecção por zika no futuro ${ }^{2}$.

Neste sentido, é importante ressaltar que apenas a mudança de comportamento da população não é suficiente quando se fala em prevenção, pois o controle vetorial só terá êxito se conseguir incorporar novas tecnologias e ferramentas que permitam uma articulação com as estratégias que já estão em vigor como mudança comportamental, desta forma será possível alcançar resultados mais satisfatórios que comprovadamente consigam diminuir a carga da doença e não apenas melhore indicadores entomológicos ${ }^{10}$. Portanto, o surgimento da categoria "prevenção" permite reflexões acerca de quais são os desafios que se colocam quando há incertezas sobre a existência do próprio risco, e qual é o papel da comunicação neste cenário, para que não seja reforçada a culpabilização dos indivíduos e de propostas individualizantes para evitar $\operatorname{riscos}^{9}$. As ações do governo foram assuntos também abordados com frequência pelo jornal. Essa categoria emergente demonstra a preocupação da imprensa em apresentar a população que a autoridade pública tem desenvolvido ações de combate e controle. Logo, mesmo em meio a uma situação de risco, é colocado em evidência pelo JTO que 
as devidas providências frente ao problema estão sendo tomadas, como demonstram os trechos abaixo:

“O governo intensificou o combate ao aedes aegypti” (JTO, 06/03/2016)

"SUS publica plano para tratar crianças. Acolhida, proteção social, prevenção de doenças associadas ao vetor são parte da estratégia do governo” (JTO, 12/04/2016)

Da mesma forma, se coloca a abordagem sobre tratamento e recuperação. Tal categoria se relaciona intimamente com o surgimento da microcefalia associada à infecção por zika vírus. A preocupação com o tratamento dos bebês diagnosticados com zika e com as pessoas infectadas pelo vírus era uma constante do jornal. A realização ou não de tratamento e o acesso ao serviço de saúde foi abordado com frequência, como os trechos a seguir evidenciam:

"Segundo a SESAU todas as gestantes, mães e bebês do Estado estão recebendo o tratamento adequado" (JTO, 15/12/2015)

"O Ministério da Saúde (...) publicou um plano de ação para o combate do mosquito aedes aegypti e para garantir a proteção social de crianças com microcefalia" (12/04/2016)

A abordagem do jornal no tocante ao acompanhamento das crianças é sobre a não existência de um tratamento e diagnóstico específico para as consequências da zika, dado que foi enfatizado pela imprensa em trechos como o que segue abaixo:

“O Ministério da Saúde mudou os critérios de diagnostico de Microcefalia relacionada ao virus Zika” (JTO, 05/12/2015) 
Neste sentido, coloca-se a importância da definição de protocolos para o tratamento de casos agudos (em particular para as mulheres grávidas) e formas para manejo das consequências dos efeitos fetais graves e incapacitantes ${ }^{11}$.

\section{Zika na Capa e elementos gráficos: o que mais chamou atenção?}

Em relação aos elementos gráficos presentes nos textos jornalísticos, observouse a presença de fotos, infográficos, tabelas e mapas em 39 dos 44 textos analisados. As fotos tiveram um maior protagonismo, mas todos os elementos gráficos são ferramentas que ajudam a chamar atenção do leitor para a notícia.

Tabela II. Elementos Gráficos nos Textos Jornalísticos

\begin{tabular}{l|c}
\hline \multicolumn{1}{c|}{ Elemento Gráfico } & $\mathrm{N}^{\text {o de Codificações }}$ \\
\hline Fotos & 39 \\
\hline Infográficos & 19 \\
\hline Tabelas & 3 \\
\hline Mapas & 2 \\
\hline
\end{tabular}

Fonte: Elaboração Própria.

Foram analisados também os gêneros jornalísticos utilizados pelo periódico, as reportagens foram mais frequentes, totalizando 41 enquanto as notícias apareceram cinco vezes.

As fotos dão destaque ao cenário vivido, os infográficos permitem a melhor visualização das informações mais relevantes, enquanto as tabelas trazem informações quantitativas importantes que dão um panorama numérico dos casos da doença e o mapa trás o cenário nacional dos casos. É importante a presença de tais elementos no jornal, para a divulgação fidedigna das informações referentes ao tema. 
As notícias sobre Zika foram capa do jornal 22 vezes nos quatro anos. A capa traz o que o jornal concidera importante e relevante. Levando em concideração que o total de textos sobre zika foi 44 , metade deles estavam na capa, demonstrando que o tema é muito relevante.

Percebe-se que o jornal teve, no período analisado, uma preocupação em trazer esses elementos acompanhando seus textos jornalísticos, porém quando levamos em consideração os quatro anos de análise, com apenas vinte e duas capas referentes ao zika, entende-se que o período de maior preocupação com a temática por parte do jornal tende a mudar no decorrer do ano, assim como suas prioridades para compor a capa. $\mathrm{O}$ período em que os casos relacionados à zika estiveram na capa, foram os períodos de aumento de casos da doença e de microcefalia no estado, configurando estado de emergência.

Na comunicação, esse cenário de emergência gera um valor-noticia, ou seja, tem importancia no ponto de vista do jornalista e quando publicado entra na agenda do público receptor se integrando ao fluxo de informações que interessam a população. Os valores-noticia são agrupados em categorias, desta forma, uma emergência de zika pode ser agrupada por sua importância em categorias como ${ }^{12}$ :

I. "Impacto sobre a nação e o interesse nacional" , pois, implica o grau de significado e importância, de proximidade geográfica, do atingimento do imaginário da população.

II. "Quantidade de pessoas envolvidas no acontecimento", tendo em vista o grande número de informações sobre o número de casos. Quanto maior o número de pessoas envolvidas, maior a noticiabilidade, ou seja, muitos casos notificados da doença tem maior impacto do que pouca notificação, nos períodos de maior número de casos, apareceram mais capas no jornal sobre zika. 
III. "Relevancia e significação do acontecimento quanto a sua potencial evolução e consequência" fotos que apresentam consequências a se desdobrarem num tempo futuro a exemplo da microcefalia, correspondem mais aos critérios jornalísticos do que aqueles que se esgotam em si mesmos.

\section{Foco do jornal: Saúde ou Doença?}

Em relação ao foco dos textos, a doença se destacou, sendo o foco de 99 codificações, enquanto a saúde apareceu como foco 15 vezes. É fato que o objeto de estudo é o vírus zika, desta forma é esperada mais frequência do jornal em informar sobre a doença em si, trazendo um panorama relacionado à prevenção, diagnóstico, tratamento e sintomas. Percebe-se que, mesmo quando o texto jornalístico menciona saúde, ela está relacionada com a qualidade de vida das pessoas diagnosticadas ou com suspeita de zika ou microcefalia. A saúde está intimamente ligada com o tratamento, como demonstram os trechos a seguir:

“Estimulação precoce pode ajudar a recuperar lesões" (JTO, 25/06/2017)

"Ela desenvolveu bastante. Antes ela era meio durinha, não abria a mão, não acompanhava as coisas. Agora ela está usando óculos, já abre as mãozinhas. Agora começou a querer sentar, mas ainda não está segurando o tronco. Mas tenho fé em Deus que ela vai conseguir" Conta a mãe. (JTO, 25/06/2017)

Entende-se que, a forma e o momento em que a notícia é veiculada, produzem significados distintos nos leitores. Tais significados podem produzir uma mobilização popular e o esclarecimento das pessoas, ou a disseminação de medo e preocupação constante, a depender da abordagem. Na saúde, o processo de publicização deve ser 
avaliado com suas dimenções, que podem produzir educação em saúde, ou instalar um cenário de pânico a depender da "rotulagem da doença" pois quando se nomeia o problema, a abordagem do assunto e a criação de debates públicos tornam-se mais fáceis. Portanto, informar de forma emancipatória pode ser um instrumento para a ação, visto que a forma como se constroi a informação é decisiva para definir as imagens do público sobre a realidade e suas construções simbólicas ${ }^{13}$.

\section{Povo: fala de menos, culpado demais.}

Uma predominância presente na análise foi a responsabilização pela epidemia de zika ser atribuída à população em detrimento do poder público, que foi citado como responsável pelo problema poucas vezes. Os profissionais e o serviço de saúde também foram colocados como responsáveis em algum momento.

Tabela III. Responsabilização

\begin{tabular}{l|c}
\hline \multicolumn{1}{c|}{ Ente responsabilizado } & No de Codificações $^{\circ}$ \\
\hline População & 41 \\
\hline $\begin{array}{l}\text { Profissional/Serviço de } \\
\text { Saúde }\end{array}$ & 11 \\
\hline Governo & 8 \\
\hline Fonte: Elaboracão Própria
\end{tabular}

Fonte: Elaboração Própria.

Percebe-se que o jornal tende a isentar o poder público da responsabilidade perante a epidemia no decorrer dos textos jornalísticos, pois o foco está voltado majoritariamente para o comportamento da comunidade, mesmo sabendo que o Estado é um dos principais responsáveis por não conseguir o efetivo controle ${ }^{1}$. 
Em grande parte das reportagens, as ações de combate do governo estão em evidência, e ao mesmo tempo, há um redirecionamento do foco da responsabilidade às comunidades e famílias, segundo o trecho abaixo.

“Apesar do poder público orientar e vistoriar os imóveis, a população precisa se conscientizar que a proliferação do mosquito acontece devido à falta de cuidados diários dos moradores com seus lotes habitados e até com os terrenos baldios vizinhos" (JTO, 13/02/2016)

O jornal descreve que o poder público não consegue combater o vírus sozinho, e a população é descrita como quem por não faz a sua parte na prevenção e deixa a desejar na limpeza de seus quintais e ruas, como exemplifica os trechos a seguir.

"Só o poder público atuando não vai ter efetividade no controle do mosquito" (JTO. 17/02/2018)

"Não adianta esse mutirão se a comunidade não se convencer da importância e da simplicidade das ações de combate à doença” (JTO, 19/12/2015)

“É vergonhoso ver o que acontece em alguns quintais" (JTO, 19/12/2015)

“É necessário união e esforço, pois seu vizinho pode ser seu inimigo” (JTO, 19/12/2015)

Um estudo de Bennet et $\mathrm{l}^{14}$, colabora para o entendimento de questões relativas a culpabilização da sociedade em relação a epidemias. O autor argumenta que de um ponto de vista estimulado pela mídia, o público pode ser acusado de ignorar recomendações perfeitamente sensatas e cientificamente solidas. Por outro lado, aquelas responsáveis pelas recomendações podem ser vistos como não confiáveis, dissimulados, ou inclinados a posturas paternalistas ${ }^{14}$. 
Neste sentido, é preciso repensar a maneira como a população é retratada nas reportagens, tendo em vista que mesmo que haja uma limpeza constante nas casas, se o governo não oferecer condições dignas de saneamento básico, as ações preventivas podem não surtir efeito. Se faz necessário considerar formas menos culpabilizantes de tratar as reações defensivas quanto ao risco pelas autoridades governamentais e pelos responsáveis por políticas públicas em prevenção e promoção de saúde ${ }^{9}$. Não se trata de adotar uma posição paternalista em relação à população e criminalista para com o Estado, mas oferecer oportunidade para que seja feita uma crítica abrangente pior meio das informações veiculadas pela imprensa ${ }^{4}$. Uma relação de parceria entre a mídia, comunidade, governo e profissionais de saúde pode ser o melhor caminho para o combate ao zika e demais arboviroses ${ }^{1}$.

Ao analisar a quem o jornal deu voz, no período analisado, o interlocutor mais presente é o governo estadual colocando em evidência as ações realizadas por ele, seguido dos profissionais de saúde e da população que teve menos fala no jornal como demonstra a tabela a baixo.

Tabela IV. Interlocutores do Jornal

\begin{tabular}{l|c}
\hline \multicolumn{1}{c|}{ Interlocutor } & No de Codificações \\
\hline Governo & 45 \\
\hline Profissional de saúde & 34 \\
\hline População & 31 \\
\hline \multicolumn{2}{l}{ Fonte: Elaboração Própria }
\end{tabular}

Tal dado demonstra um paralelo entre responsabilização e representatividade no jornal, ao mesmo tempo em que a população é a maior responsabilizada pela situação epidêmica de zika é a que menos tem voz no jornal, enquanto que o governo é minimamente responsabilizado e seus representantes são os que mais aparecem no 
jornal, colocando em evidencia as ações desenvolvidas como demostram os dados a seguir.

O governo teve um papel central na informação trazida pelo jornal, pois, na maioria das vezes um representante do poder governamental a principal voz das matérias. Na maioria das vezes foram enfatizadas as ações de combate à doença realizada pelas autoridades. Percebeu-se que as vozes da população e dos profissionais de saúde ficaram em segundo plano, porem esses foram os mais responsabilizados pelos casos de zika. O foco da informação recorre a uma chamada a militarização do combate ao Zika e demais arbovírus, com menção a palavras como "força-tarefa, fiscalização e guerra ao mosquito", tais como os trechos abaixo:

"Estado participa de campanha nacional que visa combater o Aedes Aegypiti $(J T O, 13 / 02 / 2016)$

"A força-tarefa fez parte da mobilização promovida pelo governo federal para combate ao mosquito' (JTO, 03/12/2016)".

Ferraz destaca que "palavras como ação, controle e combate estão muito presentes nos discursos atuais da saúde pública, sendo necessária a implementação de verdadeiras táticas de guerra para conter a expansão do mosquito transmissor da doença"15 o que pode ser observado com frequência nas falas do governo no jornal. Importa criar discussões para alcançar um ambiente favorável a debates sobre riscos que vão além de recomendações autoritárias que somente apelam para mandatos moralistas de autodisciplina e autocontrole 9

\section{Número de casos: Do risco ao medo do zika vírus}

Ao abordar a epidemia de zika, a ênfase do JTO esteve em informar aos leitores os números oficiais de casos confirmados e suspeitos de zika e também de microcefalia 
no estado do Tocantins e no país. Outras abordagens relevantes estão na relação do vírus zika com outras arboviroses como dengue e chikungunya, ações de combate a doença, prevenção e educação em saúde, medo, informações sobre a doença e consequências da microcefalia. A relação dessas abordagens é demonstrada no gráfico 1.

Abordagem do jornal sobre zika - Gráfico I

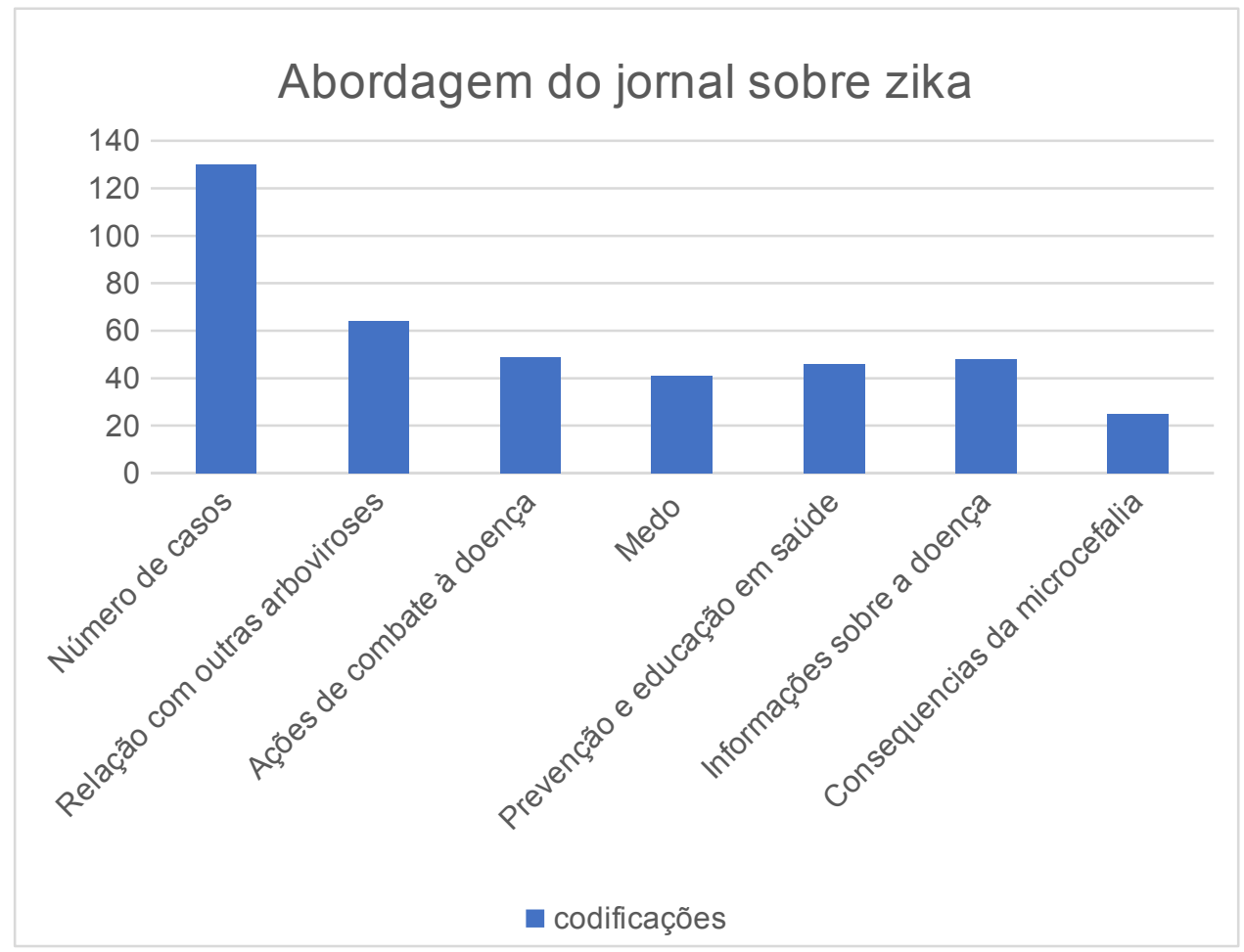

Fonte: Elaboração Própria

O foco dos textos jornalísticos é a informação sobre a quantidade de casos, seja zika ou de microcefalia, porém em alguns momentos o posicionamento do periódico tende a apelar para o sensacionalismo e o amedrontamento da sociedade, especialmente, 
das mulheres em situação de gravidez que vivem no Nordeste do Brasil como mostra os trechos a seguir.

"Zika vírus já chegou, microcefalia preocupa” (JTO, 20/11/2015)

"Microcefalia, mal que assusta" (JTO, 25/06/2017)

“Aedes Aegypti: conhecendo o inimigo” (JTO, 04/01/2016).

Dines ${ }^{16}$ divide, para fins didáticos, o sensacionalismo em três grupos: gráfico, linguístico e temático. O gráfico é aquele que se dirige a leitores desacostumados com a leitura, privilegia letras grandes e conceitos pequenos e apresenta descompasso entre a importância do fato e a ênfase visual. O sensacionalismo linguístico ou de texto inclui as opções pelas palavras vivas e ricas que provocam sensações, e o temático é ligado às matérias que vendem ${ }^{16}$, dessa forma, tem uma estreita ligação com os valores-noticia elencados pela mídia em questão, visto que, o que se torna valor-notica é exatamente o que interessa o leitor e gera lucro ao ser vendido ${ }^{11}$.

$46 \%$ dos textos jornalísticos abordam como prevenir o aumento do número de casos e como se cuidar frente ao risco, é um paralelo que os textos jornalísticos demonstram frisar o número de casos pode trazer um maior amedrontamento, como também pode incentivar o combate de maneira mais efetiva, dessa forma, o jornal pode utilizar em alguns momentos o sensacionalismo linguístico, como nos exemplos a seguir.

“Casos suspeitos de Zika aumentam 188\% no Estado” (JTO, 11/03/2016)

“Microcefalia: Casos não param de crescer no Tocantins" (JTO 29/12/2015)

Quando é colocada em evidencia uma má notica como um aumento de $188 \%$ dos casos de zika e o crescimeto da microcefalia, com letras grandes que chamam 
atenção, sensações de medo podem ser provocadas no leitor, configurando sensacionalismo linguistico ${ }^{16}$.

Outra questão destacada na abordagem do jornal é a relação da zika com as demais arboviroses transmitidas pelo mesmo vetor, tais como a dengue e a chikungunya. A abordagem da zika na mídia raramente se dá de forma isolada. Em 64\% das vezes, considerando o total de reportagens, as informações sobre zika fazem um paralelo com outras arboviroses, tendo em vista que a doença tem como transmissor o mesmo vetor da dengue e da chikungunya e que juntas causam uma tríplice epidemia, por exemplo:

"O perigo de deixar o mosquito Aedes Aegypti nascer está nas doenças que ele transmite como, zika, dengue e chikungunya" (JTO, 04/03/2016).

Neste cenário, as mesmas ações de combate são realizadas para as três arboviroses, que tem sintomas semelhantes, mas tratamentos e diagnósticos específicos. Percebe-se que há uma preocupação do jornal em esclarecer para a população o que diferencia as três doenças no tocante a sintomas, diagnóstico e tratamento, tal como alertar para a prevenção da proliferação do mosquito que evita o surgimento das três doenças, como demonstram os trechos a abaixo.

"Com sintomas parecidos, doenças incapacitam vitimas por causa da febre alta e das dores no corpo. Todas podem matar" (JTO, 24/11/2017)

"Novo vírus tem sintomas mais brandos que a dengue, mas é transmitido pelo mesmo mosquito, o Aedes Aegypiti” (JTO, 15/05/2016)

"Para dar fim ao mosquito transmissor da dengue e também do zika vírus e chikungunya, acontece hoje a segunda mobilização das Forças Armadas em todo o país" (JTO, 13/02/2016) 


\section{Zika e Microcefalia}

A relação entre a zika e a microcefalia em bebês é um dos temas centrais dos textos jornalisticos. Tal relação foi mencionada e dada destaque pelo jornal totalizando 108 codificações ao longo dos quatro anos de análise, seguem alguns exemplos.

"Microcefalia: Aumentam casos e preocupação, país tem 41 casos de Microcefalia por Zika” (JTO, 04/01/2016)

“Tocantins confirma 17 casos de Microcefalia” (JTO, 25/06/2016)

"Ligação do Zika vírus com Microcefalia muda rotina de mulheres grávidas na capital” (JTO, 04/12/2015)

Muitas questões emergem da epidemia da "síndrome congênita do zika", que engloba casos de microcefalia e/ou outras alterações do Sistema Nervosas Centrais associadas à infecção pelo vírus ${ }^{17}$, especialmente no que diz respeito à divulgação de notícias pela mídia. Há um cuidado importante que precisa ser tomado pelos profissionais da comunicação ao noticiar um cenário de incertezas que causa reação de medo nos leitores. A comunicação de risco deve ser uma aliada no processo de disseminação das informações para não causar um efeito indesejado.

O cenário de incerteza colocado diante das pessoas afetadas no início da epidemia poderia causar um caos social, pois há muitas perguntas ainda sem respostas? A preocupação do jornal estava em sempre esclarecer aos leitores quais eram as novas notícias sobre o tema, focando sempre na prevenção e na informação do que é a doença e como tratar os afetados.

Sabe-se que a microcefalia resulta no desenvolvimento anormal do cérebro, e as consequências futuras de tal acometimento dependem das anormalidades cerebrais 
subjacentes que, podem variar de atrasos moderados no desenvolvimento até a deficiência motora e intelectual severa ${ }^{18}$. Informar a população com responsabilidade acerca de tal cenário é um grande desafio aos profissionais da comunicação, visto a delicadeza do cenário e seus riscos. Outra medida de igual importância para a divulgação de informações verídicas e úteis à população está na necessidade de haver um esforço da comunidade científica e dos serviços de saúde para que as avaliações e o acompanhamento de crianças com microcefalia e pessoas com Zika sejam feitos com o uso de instrumentos validados para o Brasil e que possam ser incorporados na linha de cuidados às crianças e famílias ${ }^{19}$.

\section{4) Considerações Finais}

Os meios de comunicação podem ser aliados na disseminação de notícias confiáveis que são indispensáveis para informar a comunidade. Este estudo demonstrou que os efeitos da zika no Tocantins foram de relevância, e a temática esteve presente no jornal em todos os anos analisados, desta forma, cumpriu-se os objetivos do estudo ao descrever o que o jornal tem veiculado sobre zika e quais aspectos tem dado maior importancia.

A prevenção e informações oficiais da dimensão da doença no estado são os aspectos mais destacos no jornal ao longo dos quatro anos. Ao notificar o número de casos com frequencia, o periódico monstra que os comportamentos, atitudes e práticas dos afetados são importantes para o enfrentamento do problema. As vozes presentes no jornal trazem uma reflexão importante a cerca da vizibilidade do governo no jornal e seu paralelo com a culpabilização da sociedade no tocante a arboviroses. 
O estudo trouxe apontamentos importantes, principalmente ao analisar a mídia em uma localidade não muito explorada pelos estudos de comunicação em saúde e que foi fortemente afetada pela doença. Por isso, os estudos sobre a imprensa e o Zika devem ser mais desenvolvidos na região norte e nordeste do país. Cabem novos estudos que se aprofundem no processo de produção desses textos e na compreensão dos jornalistas sobre o tema.

\section{5) Referências}

1. Porto, RM; Costa, PRSM. O Corpo Marcado: a construção do discurso midiático sobre Zika Vírus e Microcefalia. Cadernos de Gênero e Diversidade, v. 3, n. 2, 2017. 2. Araújo IS; Cardoso JM. Comunicação e Saúde. Rio de Janeiro: Editora FIOCRUZ, 2007.

3. Herte de Moraes, C; Beling Loose, E; Tourinho Girardi, I. Dengue, zika e chikungunya: análise da cobertura do risco de doenças associadas às mudanças climáticas sob a ótica do jornalismo ambiental. Anuario Electrónico de Estudios en Comunicación Social “Disertaciones”. 2017; 10(2), 120-132.

4. Langbecker, Andreaet al. A cobertura jornalística sobre temas de interesse para a Saúde Coletiva brasileira: uma revisão de literatura. Interface - Comunicação, Saúde, Educação [online]. 2019, v. 23

5. Cao-Lormeau, VM; Blake, A; Mons, S; Lastère, S; Roche, C; Vanhomwegen, J.\& Vial, AL. Guillain-Barré Syndrome outbreak associated with Zika virus infection in French Polynesia: a case-control study. The Lancet, 2016, 387(10027). 
6. Ministério da Saúde (BR), Secretaria de Vigilância em Saúde. Boletim Epidemiológico - Monitoramento dos casos de dengue, febre de chikungunya e febre pelo vírus Zika até a Semana Epidemiológica 54. Bol Epidemiológico.

7. Bardin. L. Análise de conteúdo. Lisboa: Editora Edições 70, 1977

8. Ministério da Saúde. Vírus Zika no Brasíl: A resposta do SUS. $1^{\text {a }}$ edição. Brasília, Brasil: Editora MS. 2017.

9. Castiel LD; Vasconcellos-Silva PR; Moraes DR. Micromortevida Severina? A comunicação preemptiva dos riscos. Cad. Saúde Pública. 2017, 33(8).

10. Achee NL; Gould F; Perkins TA; Reiner RC; Morrison AC; Ritchie SA; et al. A critical assessment of vector control for dengue prevention. PLoS Negl Trop Dis. 2015; $9(5)$.

11. Santos, CQ; Cardoso, AMP. Inclusão digital e desenvolvimento local. TransInformação, Campinas, 2009, 21(1): p. 7-22, jan./abr.

12. Hohlfeld A; Martinho LC; França VV. Teorias da Comunicação: Conceitos, escolas e tendencias. $15^{\mathrm{a}}$ ed. Pedropolis, RJ: Editora Vozes, 2015.

13. Cavaca, AG et al.'Valor-saúde': critérios epidemiológicos potenciais para a comunicação e saúde. RECIIS - Revista Eletrônica de Comunicação, Informação e Inovação em Saúde, Rio de Janeiro, v. 12, n. 1, p. 26-42, jan./mar. 2018.

14. Bennett P; Calman K; Curtis S; Fischbacher-Smith D. Understanding public responses to risk: issues around policy and practice. In: Bennet, P., Calman, K., Curtis, S. and Fischbacher-Smith, D. (eds.) Risk Communication and Public Health. Oxford University Press: Oxford, pp. 3-22.

15. Ferraz MR; Gomes MAM. Epidemia e memória: narrativas jornalísticas na construção discursiva sobre a dengu. Dissertação (Mestrado). Programa de PósGraduação em Comunicação, Universidade Federal de Pernambuco, Recife, 2010.

16. Dines, A. Sensacionalismo na Imprensa. Comunicações e Artes. Uma Semana de Estudos sobre Sensacionalismo, São Paulo, n. 4, p. 67 -75, 1971.

17. Diniz, D. Vírus Zika e mulheres. Cad. Saúde Pública, Rio de Janeiro, v. 32, n. 5, 2016 .

18. Tomal NR. Zika vírus associado à microcefalia. Revista de Patologia do Tocantins, v. 3, n. 2, p. 32-45, 2016.

19. Brunoni D et al . Microcefalia e outras manifestações relacionadas ao vírus Zika: impacto nas crianças, nas famílias e nas equipes de saúde. Ciênc. saúde coletiva, Rio de Janeiro , v. 21, n. 10, p. 3297-3302, Oct. 2016 
ISBN: $3588-65-80968-15-2$

Galoá $\{$ Este trabalho foi publicado utilizando o Galoá proceedings https://proceedings.science/p/113751 ?lang=pt-br 